\title{
Novel anticancers and dermatological adversities: old rivals but new challenges
}

\author{
Kamal Kant Sahu, Ajay Mishra, Iryna Chastain
}

Department of Internal

Medicine, Saint Vincent Hospital, Worcester, Massachusetts, USA

\section{Correspondence to} Dr Kamal Kant Sahu, drkksahu85@gmail.com

Accepted 3 November 2018

\section{DESCRIPTION}

A 68-year-old ex-smoker with 5-year history of controlled hypertension on once daily dose of losartan $25 \mathrm{mg}$ presented with breathlessness of 2 months duration. X-ray showed right-sided pleural effusion. CT chest also confirmed huge lung mass with moderate right pleural effusion (figure 1A). The pleural fluid cytology was positive for malignant cells. PET scan showed homogeneous hypermetabolism of conglomerate mass/adenopathy with maximum standardized uptake value of 6.8 (figure 1B,C). Diagnosis of stage IV lung adenocarcinoma with malignant pleural effusion was made. He was started treatment with a 3 -weekly cycle of pemetrexed $\left(500 \mathrm{mg} / \mathrm{m}^{2}\right.$ intravenous once on day 1$)$ and pembrolizumab (200 mg intravenous on day 1$)$. At the end of third cycle, he noticed itchy rashes all over his body. It was initially on his back and then spread downwards involving his trunk, arms and legs. He denied any history of fever or chills. Skin examination showed diffuse ill-defined erythematous maculopapular rash over the back, chest and abdomen (figure 2A,B). At places few nodules were present. Diffuse erythematous to violaceous patch was present over the lower one-third of bilateral lower limbs (figure 2C). Based on the history and clinical features, a probable diagnosis of maculopapular rash secondary to anticancer drugs was made. We offered skin biopsy for further evaluation, but the patient refused. Further chemotherapy was withheld, and he was started on oral prednisolone $0.5 \mathrm{mg} / \mathrm{kg}$ once daily dose and syrup diphenhydramine $\mathrm{HCl}$ ( $25 \mathrm{mg}$ every 8 hourly). Clinical examination after 2 weeks showed fading of skin lesions. Patient opted out of any more anticancer treatment and enrolled for palliative care. Inability to obtain a skin biopsy limited the ability to histologically differentiate and identify the responsible drug in our case.

Patients with stage IV disease who are treated with immunotherapy can have an average overall survival anywhere from 18 to 24 months. Our patient received two newer anticancer drugs which were the probable cause of skin rash. Immune checkpoint inhibitors (eg, pembrolizumab) targeting programmed death ligand-1 (PD-1) on tumour cells are recently used in the treatment of several cancers. As pembrolizumab is an immune modulator, it can topple the immune homeostasis against body's own cells leading to immune-related adverse effects like pneumonitis, colitis, hepatitis, hypothyroidism, hyperthyroidism, nephritis, etc. ${ }^{1}$

Similarly, pemetrexed is a novel anti-folate antimetabolite agent that is also rarely known to cause skin rashes. Manufacturers of pametrexed have recommended premedication with 5-7 days of folic acid and 3 days with dexamethasone $4 \mathrm{mg}$ twice daily on the day before, the day of and the day after infusion. Despite following premedication scheme, our patient still experienced skin rashes.

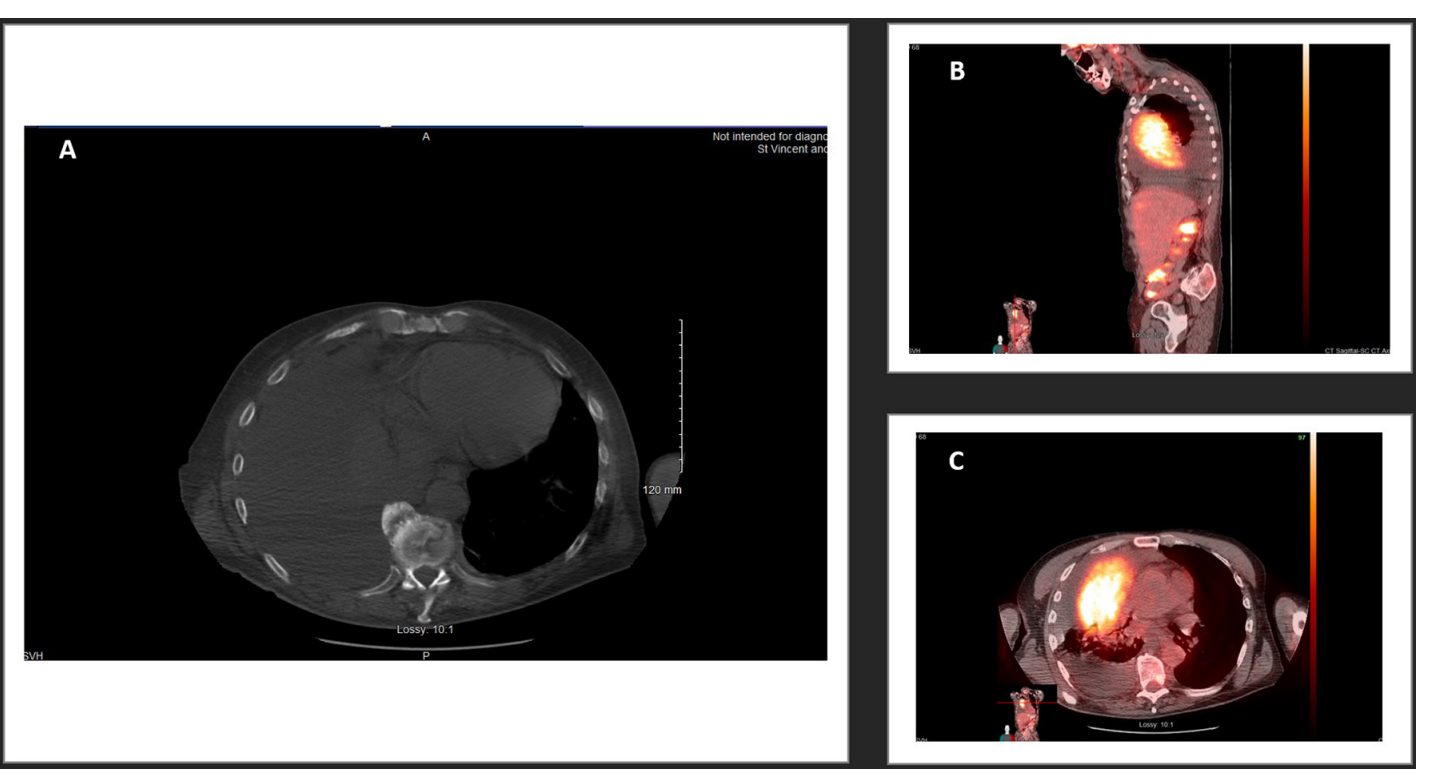

Figure 1 (A) Complete collapse of the right upper and right middle lobes. Mass effect from underlying mass, which is inseparable from the mediastinum/right hilum and adjacent collapsed lung. (B) Sagittal and (C) axial. PET showing homogeneous hypermetabolism of the collapsed lobes with maximum SUV 6.8. 


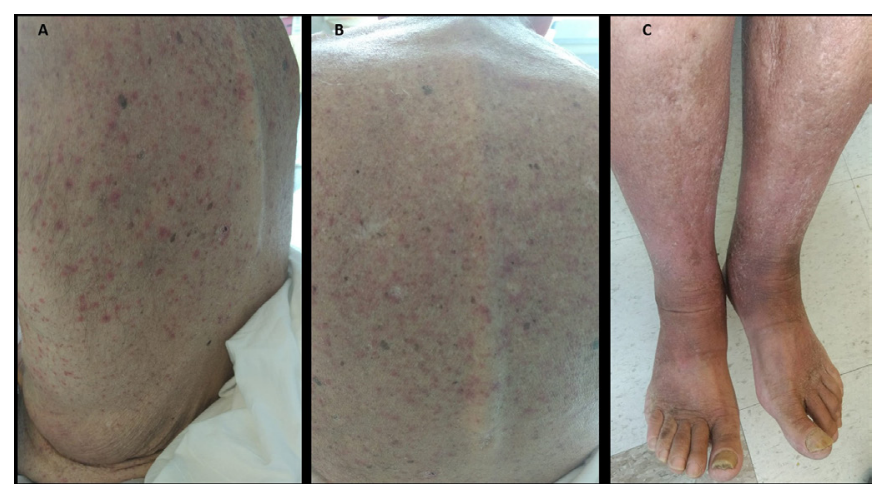

Figure $2(A, B)$ Skin examination showed diffuse ill-defined erythematous maculopapular rash over the back, chest and abdomen. (C) Diffuse erythematous to violaceous patch was present over the lower third of lower limbs.

Immune-mediated skin rashes can range from simple dry skin to fatal Stevens-Johnson syndrome (SJS)/toxic epidermal necrolysis (TEN) complex. Depending on the severity and grade of skin reactions, immune therapies can be withheld for a while or discontinued permanently. It is also important to adequately evaluate and rule out other possible aetiologies of skin lesions like infection, tumour infiltration, etc.

In a study including 88 patients of advanced melanoma on pembrolizumab, the most common AEs were cutaneous. ${ }^{1}$ Similarly, cutaneous AES were reported in $40 \%-60 \%$ of patients on pembrolizumab in other studies as well. Most common cutaneous AEs identified were maculopapular rash, followed by pruritus and hypopigmentation. Other cutaneous manifestations that have been reported are vesicles, blisters and psoriasiform lesions. ${ }^{12}$ Mucosal involvement in the form of necrotic ulcerations of lip, and erosive oral mucositis, blepharoconjunctivits have also been reported. ${ }^{2}$ Recently, Kunimasa et al reported interesting case of pembrolizumab-related skin rash. They found extensive CD8 (+) PD-1 (+) T-cell infiltration in the immunofluorescence analysis of the skin biopsy. ${ }^{3}$ They proposed revival of immune cells as the cause of skin rash during antiPD1 therapy. Recent studies have not shown any evidence of worst outcome among patients developing cutaneous AEs as well. Most patients with cutaneous AEs respond well to topical steroids like betamethasone.

Similarly, pemetrexed can cause a variety of cutaneous AEs like alopecias, TEN, urticarial vasculitis, exanthematous pustulosis, radiation recall dermatitis, etc. Likely mechanism may be due to (1) direct cytotoxic effect due to arrest of cell cycle 'S phase' leading to cell necrosis or (2) indirect immune reaction. Piérard et al suggested that a high Ki67 index could point towards cell cycle blockade versus calprotectin (MAC 387) immunopositivity of keratinocytes as a soft indictor of immunological perturbation. ${ }^{4}$ Usui et al in their study concluded that mandatory dexamethasone as premedication before pemetrexed-based therapy reduced the frequency of grade $\geq 2$ skin rash by at least $10 \%{ }^{5}$ In past, many anti-cancer drugs are reported to be associated with dermatological adverse effects ${ }^{(6,7)}$. More studies are needed to know the exact pathophysiology behind the cutaneous AEs and for possible remedies.

\section{Learning points}

- Knowledge of cutaneous adverse events would prevent unnecessary investigations and expedite the treatment.

- Premedication before immunotherapies is advisable but may not avert immune-related adverse effects in every case.

- Thorough examination of patient in every visit is mandatory before prescribing the next cycle of chemoregimen.

Acknowledgements The authors thank Dr Ann George, Dr Anu Anna George and Dr Gitesh U Sawtakar for their support and contribution during writing up of this manuscript.

Contributors KKS: case writing and discussion, planning and reporting. AM: photography, made legends and review of the manuscript. IC: management, editing and review of literature, conception and design.

Funding The authors have not declared a specific grant for this research from any funding agency in the public, commercial or not-for-profit sectors.

Competing interests None declared.

Patient consent Obtained.

Provenance and peer review Not commissioned; externally peer reviewed.

\section{REFERENCES}

1 Sanlorenzo M, Vujic I, Daud A, et al. Pembrolizumab cutaneous adverse events and their association with disease progression. JAMA Dermatol 2015;151:1206-12.

2 Khokhar MO, Kettle J, Palla AR. Debilitating skin toxicity associated with pembrolizumab therapy in an 81-year-old female with malignant melanoma. Case Rep Oncol 2016:9:833-9.

3 Kunimasa K, Isei T, Nakamura H, et al. Proliferative CD8(+) PD-1(+) T-cell infiltration in a pembrolizumab-induced cutaneous adverse reaction. Invest New Drugs 2018;375.

4 Piérard-Franchimont C, Quatresooz P, Reginster MA, et al. Revisiting cutaneous adverse reactions to pemetrexed. Oncol Lett 2011;2:769-72.

5 Usui N, Kondo Y, Ryota N, et al. Mandatory dexamethasone strictly monitored by pharmacists reduces the severity of pemetrexed-induced skin rash. Eur J Hosp Pharm Sci Pract 2017;24:283-5.

6. Sahu KK, Sawatkar GU, Jeyaraman P, et al. Bullae and blisters: a rare case of bendamustine skin toxicity. Indian J Hematol Blood Transfus 2016;32(suppl 1):368-9.

7. Sawatkar GU, Sahu KK, Prakash G, et al. Image gallery: flagellate dermatitis. Br J Dermatol 2016;174:e23.

Copyright 2018 BMJ Publishing Group. All rights reserved. For permission to reuse any of this content visit

https://www.bmj.com/company/products-services/rights-and-licensing/permissions/

BMJ Case Report Fellows may re-use this article for personal use and teaching without any further permission.

Become a Fellow of BMJ Case Reports today and you can:

- Submit as many cases as you like

- Enjoy fast sympathetic peer review and rapid publication of accepted articles

- Access all the published articles

- Re-use any of the published material for personal use and teaching without further permission

For information on Institutional Fellowships contact consortiasales@bmjgroup.com

Visit casereports.bmj.com for more articles like this and to become a Fellow 